\title{
Comparison of the pharmacologic and clinical profiles of new combined oral contraceptives containing estradiol
}

This article was published in the following Dove Press journal:

Open Access Journal of Contraception

29 November 2013

Number of times this article has been viewed

\section{Jeffrey $T$ Jensen' \\ Johannes Bitzer ${ }^{2}$ \\ Marco Serrani ${ }^{3}$}

'Department of Obstetrics and Gynecology, Oregon Health and Science University, Portland, OR, USA; ${ }^{2}$ Department of Social Medicine and Psychosomatics, Women's Hospital, University Hospital of Basel, Basel, Switzerland; ${ }^{3}$ Global Medical Affairs, Women's Healthcare, Bayer HealthCare Pharmaceuticals, Berlin, Germany
Correspondence: Jeffrey $T$ Jensen Department of Obstetrics and Gynecology, Oregon Health and Science University, 318I SW Sam Jackson Park Road, Portland, OR 97239, USA

$\mathrm{Tel}+\mathrm{I} 5034945 \mathrm{II} 3$

$\mathrm{Fax}+\mathrm{I} 5034945083$

Email jensenje@ohsu.edu
Abstract: Three estradiol $\left(\mathrm{E}_{2}\right)$-containing oral contraceptives, estradiol valerate/cyproterone acetate $\left(\mathrm{E}_{2} \mathrm{~V} / \mathrm{CPA}\right.$, Femilar $\left.{ }^{\mathbb{B}}\right)$, estradiol valerate/dienogest $\left(\mathrm{E}_{2} \mathrm{~V} / \mathrm{DNG}\right.$, Qlaira $\left.{ }^{\mathbb{B}} / \mathrm{Natazia}^{\mathrm{TM}}\right)$, and estradiol/nomegestrol acetate $\left(\mathrm{E}_{2} / \mathrm{NOMAC}\right.$; Zoely $\left.{ }^{\circledR}\right)$, have received approval for use in general practice. Only Finnish women currently have access to all three $\mathrm{E}_{2}$-based formulations. $\mathrm{E}_{2} / \mathrm{NOMAC}$ is currently approved only in Europe, while $\mathrm{E}_{2} \mathrm{~V} / \mathrm{DNG}$ is approved globally. To assist clinicians counseling women considering use of one of these formulations, we conducted a review of the published information about the current $\mathrm{E}_{2}$-containing oral contraceptives. A literature search was conducted using the Ovid interface and a combination of free search terms relevant to estradiol and oral contraception to identify suitable articles for inclusion in this review. The available data show that $\mathrm{E}_{2} \mathrm{~V} / \mathrm{DNG}, \mathrm{E}_{2} / \mathrm{NOMAC}$, and $\mathrm{E}_{2} \mathrm{~V} / \mathrm{CPA}$ are all effective oral contraceptives. While direct comparisons are lacking, indirect evidence suggests that $\mathrm{E}_{2} \mathrm{~V} / \mathrm{DNG}$ and $\mathrm{E}_{2} / \mathrm{NOMAC}$ may have better bleeding profiles than $\mathrm{E}_{2} \mathrm{~V} / \mathrm{CPA}$. $\mathrm{E}_{2} \mathrm{~V} / \mathrm{DNG}$ is also approved for the treatment of heavy menstrual bleeding. Both $\mathrm{E}_{2} \mathrm{~V} / \mathrm{DNG}$ and $\mathrm{E}_{2} / \mathrm{NOMAC}$ have minimal influence on hemostatic, lipid, and carbohydrate metabolism parameters, or induce less change in these parameters relative to ethinylestradiol-based oral contraceptives. However, the predictive value of these surrogate parameters is a matter of debate, and whether these differences can be translated into meaningful clinical outcomes needs to be established in large-scale, post-marketing, prospective, Phase IV cohort studies. Future studies are required to determine whether $\mathrm{E}_{2}$-based oral contraceptives confer additional benefits compared with those of ethinylestradiol-based COCs.

Keywords: estradiol valerate, dienogest, nomegestrol acetate, cyproterone acetate

\section{Introduction}

Over the last 50 years, refinements in the formulation of combined oral contraceptives (COCs) have focused on improving their tolerability and safety. Primary modifications include a reduced ethinylestradiol (EE) dose and incorporation of new progestins with improved selectivity profiles which are closer in function to natural progesterone. ${ }^{1}$ Drospirenone (DRSP), dienogest (DNG), and nomegestrol acetate (NOMAC) are the most recent progestins introduced to the market, and products containing nestorone and trimegestone are in development.

Although the contraceptive effects of COCs are mainly achieved through progestin alone, estrogen remains an important component because its inclusion enhances contraceptive efficacy and helps regulate bleeding. While the type of progestin and dosing regimen used may affect overall cycle control, ${ }^{2} \mathrm{COCs}$ with lower EE doses tend to have poorer cycle control (ie, unscheduled bleeding and/ 
or spotting) relative to formulations with the same progestin and a higher EE dose. ${ }^{2-4}$ Very low-dose EE products administered in a 24/4 and 26/2 regimen (15 $\mu \mathrm{g}$ in combination with gestodene $60 \mu \mathrm{g},{ }^{5}$ and $10 \mu \mathrm{g}$ in combination with norethindrone acetate $1 \mathrm{mg},{ }^{6}$ respectively) have been approved. Although EE $15 \mu \mathrm{g} /$ gestodene $60 \mu \mathrm{g}$ appears to have acceptable cycle control and tolerability, ${ }^{7,8}$ no data are available for EE $10 \mu \mathrm{g} /$ norethindrone acetate $1 \mathrm{mg}$. Although the reduction of the EE dose to less than $50 \mu \mathrm{g}$ has greatly improved the cardiovascular safety profile of combined pills, the benefit of dose reduction to $20 \mu \mathrm{g}$ or lower has not been definitively established. ${ }^{9}$ Even with modern "low-dose" EE formulations, factors related to hepatic and carbohydrate metabolism, as well as hemostasis, may be maintained at an upregulated level. Biological potency of estrogens depends on ligand-receptor interactions plus the rate of absorption, distribution, metabolism, and elimination. For EE, both its receptor binding affinity and its biological potency with regard to various clinical and metabolic parameters are usually greater than with estradiol $\left(E_{2}\right) .{ }^{10,11}$ Reliance on the use of EE in COCs has largely been due to its higher oral bioavailability (38\%-48\%) compared with other estrogens. ${ }^{10}$ Inclusion of a $17 \alpha$-ethinyl group on estradiol greatly enhances oral activity due to inhibition of hepatic metabolism, in particular, reduced metabolism to weaker estrogens. Oral EE is completely and rapidly absorbed in the gastrointestinal tract, undergoing oxidation to yield free hydroxylated and methylated active metabolites plus sulfate and glucuronide conjugates during first-pass metabolism in the gut and liver. ${ }^{12}$ In contrast, oral $\mathrm{E}_{2}$ is completely absorbed in the gastrointestinal tract and undergoes extensive metabolism to less potent estrone and estrone sulfate during the absorption process and in the liver. ${ }^{13}$ As a result, oral bioavailability of estradiol is typically only about $3 \%-6 \% .^{12}$

The higher intrinsic estrogenic activity of EE combined with the reduced degradation and active metabolites results in more pronounced effects on hepatic metabolism and hemostatic changes relative to $\mathrm{E}_{2}$. More simply put, oral EE activates the liver through both a first-pass effect and recirculation of EE, while hepatic activation of oral $E_{2}$ occurs predominantly through first pass. For this reason, even nonoral routes of EE administration result in dose-related effects on hepatic globulins. ${ }^{14}$ It has been hypothesized that using oral $E_{2}$ might reduce the relative impact on the hepatic and hemostatic effects and adverse events associated with EE, given that activation by recirculation does not occur. ${ }^{15,16}$
Early attempts to develop $\mathrm{E}_{2}$-containing oral contraceptives as alternatives to EE-based formulations showed that $\mathrm{E}_{2}$ containing formulations could achieve effective inhibition of ovulation and contraception. However, these early formulations were associated with unacceptable bleeding patterns and, thus, were suspended from further development. ${ }^{17-21}$ The bleeding problems associated with these earlier attempts to incorporate $\mathrm{E}_{2}$ into an oral contraceptive might be explained, in part, by the activity of $17 \beta$-estradiol dehydrogenase. This enzyme rapidly converts $\mathrm{E}_{2}$ (but not $\mathrm{EE}$ ) into estrone $\left(E_{1}\right),{ }^{22,23}$ an estrogen with only weak estrogenic activity that is unable to maintain stable endometrial proliferation. ${ }^{23}$ The rate of transformation of $\mathrm{E}_{2}$ to its metabolites may be influenced by some progestins, ${ }^{13}$ consequently, progestins with minimal impact on $\mathrm{E}_{2}$ metabolism and endometrial stroma stability may improve cycle stability with $\mathrm{E}_{2}$-based oral contraceptives. ${ }^{24}$

To date, only three $\mathrm{E}_{2}$-containing oral contraceptives have received regulatory approval for use in general practice. These include estradiol valerate/cyproterone acetate $\left(\mathrm{E}_{2} \mathrm{~V} /\right.$ CPA; Femilar ${ }^{\circledR}$, Bayer Oy, Turku, Finland), estradiol valerate/ dienogest ( $\mathrm{E}_{2} \mathrm{~V} / \mathrm{DNG}$; Qlaira ${ }^{\circledR} / \mathrm{Natazia}^{\mathrm{TM}}$, Bayer HealthCare Pharmaceuticals, Berlin, Germany), and estradiol/nomegestrol acetate $\left(\mathrm{E}_{2} / \mathrm{NOMAC}\right.$; Zoely ${ }^{\circledR}$; Theramex Srl, Milan, Italy). Clinicians and other family planning providers need informed guidance when counseling their patients about $\mathrm{E}_{2}$-containing oral contraceptives, because a number of factors may influence women's choice. As new data have become available, this comprehensive review seeks to compare and contrast the pharmacologic and clinical profiles of $\mathrm{E}_{2}$-containing oral contraceptives.

\section{Methods}

A systematic literature search was conducted using Ovid to search both MEDLINE and EMBASE simultaneously for clinical studies published up to February 20, 2013 on the three marketed $E_{2}$-containing COCs $\left(E_{2} V / D N G\right.$, $\mathrm{E}_{2} / \mathrm{NOMAC}$, and $\left.\mathrm{E}_{2} \mathrm{~V} / \mathrm{CPA}\right)$. The search strategy combined free text terms relevant to oral contraception and estradiol as follows: (beta estradiol OR beta estradiol OR $E_{2}$ OR natural estradiol OR natural estradiol) AND contracep* (where* is a wild character). The titles and abstracts from the electronic searches were initially assessed for relevant articles published in English. In addition, the reference lists of pertinent review articles identified were also examined for relevant studies not captured by the electronic search. Studies evaluating the pharmacologic and clinical profiles 
of these $\mathrm{E}_{2}$-containing COCs were chosen for inclusion in this review.

\section{Approved formulations and regimens}

$\mathrm{E}_{2} \mathrm{~V} / \mathrm{CPA}$ is a biphasic preparation taken in a $21 / 7$ cycle regimen (E $E_{2} \mathrm{mg} / \mathrm{CPA} 1 \mathrm{mg}$ on days 1-10, $\mathrm{E}_{2} \mathrm{~V} 2 \mathrm{mg} / \mathrm{CPA} 2 \mathrm{mg}$ on days 11-21, and a 7-day pill-free interval). The rationale for the biphasic $\mathrm{E}_{2} \mathrm{~V} / \mathrm{CPA}$ regimen has not been discussed in the literature, but phasic regimens are generally used in order to optimize control of bleeding.

$\mathrm{E}_{2} \mathrm{~V} / \mathrm{DNG}$ is taken in a $26 / 2$ cycle, with $\mathrm{E}_{2} \mathrm{~V} 3 \mathrm{mg}$ on days 1-2, E 2 V $2 \mathrm{mg} / \mathrm{DNG} 2 \mathrm{mg}$ on days 3-7, E $2 \mathrm{~V} 2 \mathrm{mg} /$ DNG $3 \mathrm{mg}$ on days 8-24, $\mathrm{E}_{2} \mathrm{~V} 1 \mathrm{mg}$ on days 25-26, and placebo on days 27-28. This specific regimen was established as the lowest effective dose of $\mathrm{E}_{2} \mathrm{~V}$ combined with DNG for efficient ovulation inhibition while maintaining acceptable bleeding control. ${ }^{25,26}$ The regimen for $\mathrm{E}_{2} \mathrm{~V} / \mathrm{DNG}$ was designed to provide phased delivery of hormones with estrogen dominance early in the cycle and progestin dominance from the mid-to-late part of the cycle. Early estrogenic dominance is thought to allow for initial endometrial proliferation and upregulation of progesterone receptors; this enhances sensitivity to mid-cyclic progestin action, leading to endometrial stroma stability at the end of the cycle, thereby resulting in predictable bleeding. ${ }^{27}$ The rationale for estradiol alone towards the end of the cycle and the short hormone-free interval is to ensure that overall estradiol levels remain relatively stable throughout each cycle (including the hormone-free interval). ${ }^{22}$

$\mathrm{E}_{2} / \mathrm{NOMAC}$ is a monophasic preparation taken over a cycle of $24 / 4$ days ( $E_{2} 1.5 \mathrm{mg} / \mathrm{NOMAC} 2.5 \mathrm{mg}$ on days $1-24$ and placebo on days 25-28). The $2.5 \mathrm{mg}$ dose of NOMAC was established as the optimum dose needed for ovulation inhibition. The $1.5 \mathrm{mg} \mathrm{E}_{2}$ dose was selected based on the dose used in estrogen replacement therapy established to provide adequate estrogen levels for prevention of osteoporosis in postmenopausal women. ${ }^{28}$ The rationale behind the 24/4 regimen for $\mathrm{E}_{2} / \mathrm{NOMAC}$ is based, in part, on the greater ovarian suppression achieved relative to the conventional $21 / 7$ regimen, which may result in a greater contraceptive margin and a shorter duration of withdrawal bleeding (compared with traditional $21 / 7$ regimen oral contraceptives), as well as decreased hormonal fluctuations (particularly for $\mathrm{E}_{2}$ ) and associated hormone withdrawal symptoms. ${ }^{29}$ The bleeding control achieved with $\mathrm{E}_{2} / \mathrm{NOMAC}$ has been hypothesized to be due to the ability of NOMAC to maintain endometrial stability through its minimal impact on endometrial $\mathrm{E}_{2}$ metabolism, which ensures sufficient $\mathrm{E}_{2}$ levels in the endometrium and thus prevents endometrial breakdown. ${ }^{24,30}$

The absolute bioavailability of $\mathrm{E}_{2}$ following oral $\mathrm{E}_{2} / \mathrm{NOMAC}$ administration was estimated to range between $1 \%$ and $5 \%,{ }^{31}$ and that following oral $\mathrm{E}_{2} \mathrm{~V} / \mathrm{DNG}$ administration to be about $3 \%-6 \% \cdot{ }^{32} \mathrm{E}_{2} \mathrm{~V}$ is rapidly hydrolyzed and converted to $17 \beta$-estradiol $\left(\mathrm{E}_{2}\right)$ during absorption in the gastrointestinal tract following oral administration (1 mg of

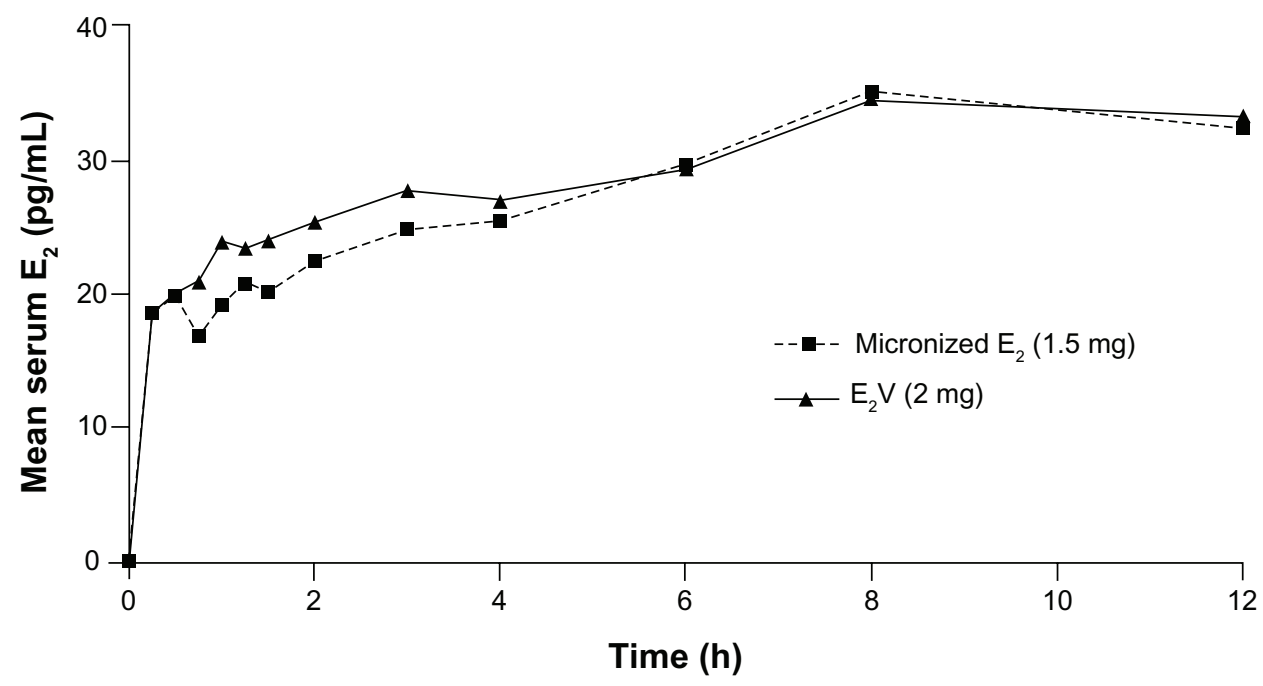

Figure I Estradiol serum concentration-time curves following single oral doses of micronized $\mathrm{E}_{2}(2 \mathrm{mg})$ and $\mathrm{E}_{2} \mathrm{~V}(2 \mathrm{mg})$. Data obtained from postmenopausal women. Note: Data used to create the figure taken with permission from Timmer CJ, Geurts TB. Bioequivalence assessment of three different estradiol formulations in postmenopausal women in an open, randomized, single-dose, 3-way cross-over study. Eur J Drug Metab Pharmacokinet. 1999;24:47-53.33

Abbreviations: $\mathrm{E}_{2}$, estradiol; $\mathrm{E}_{2} \mathrm{~V}$, estradiol valerate; $\mathrm{h}$, hours. 
$\mathrm{E}_{2} \mathrm{~V}$ contains $0.76 \mathrm{mg}$ of $\left.\mathrm{E}_{2}\right) .{ }^{23} \mathrm{The}_{2} \mathrm{E}_{2}$ pharmacokinetic profile following oral micronized $\mathrm{E}_{2}(1.5 \mathrm{mg})$ appears to be similar to that following oral $\mathrm{E}_{2} \mathrm{~V}(2 \mathrm{mg}$, Figure 1$) .^{33}$

\section{Indications and pivotal studies for approved $\mathrm{E}_{\mathbf{2}}$-containing COCs}

$\mathrm{E}_{2} \mathrm{~V} / \mathrm{CPA}$ is available in Finland only and indicated for women $>40$ years and for women aged 35-40 years for whom an oral contraceptive containing $E E$ is not appropriate. The pivotal registration study for $\mathrm{E}_{2} \mathrm{~V} / \mathrm{CPA}$ was an open-label trial that recruited 288 Finnish women aged 30-49 (mean $39.3 \pm 3.4$ ) years and was conducted over thirteen 28 -day cycles. ${ }^{34}$

$\mathrm{E}_{2} \mathrm{~V} / \mathrm{DNG}$ is available globally and is indicated for contraception and for the treatment of heavy menstrual bleeding in "women without organic pathology who desire oral contraception". The pivotal registration studies for the contraception indication included two open-label, noncomparative efficacy trials, one undertaken in Europe and the other in the US and Canada. ${ }^{35,36}$ The European study enrolled 1,377 women aged 18-50 years and was conducted over twenty 28-day cycles. ${ }^{35}$ The US and Canadian study enrolled 499 women aged $18-35$ years, and although initially planned for 13 cycles, was later extended to 28 cycles. ${ }^{36}$ This latter study, although undertaken to assess contraceptive efficacy, cycle control, and safety of $\mathrm{E}_{2} \mathrm{~V} / \mathrm{DNG}$, was not powered for a separate Pearl Index calculation. The pivotal registration studies for the treatment of heavy menstrual bleeding indication included two similarly designed, randomized placebocontrolled studies, one undertaken in Europe and Australia $(n=231)$ and the other in the US and Canada $(n=190))^{37,38}$

$\mathrm{E}_{2} / \mathrm{NOMAC}$ is available in Europe, Australia, and some South American countries, and is indicated for contraception. There were two pivotal registration studies for $\mathrm{E}_{2}$ /NOMAC, one conducted in Europe, Asia, and Australia ${ }^{30}$ and the other in the US. ${ }^{39}$ Both studies were randomized open-label, comparative trials that recruited women aged 18-50 years, of whom 3,323 were randomized to receive $\mathrm{E}_{2} / \mathrm{NOMAC}$ and 1,110 to EE/DRSP (30 $\mu \mathrm{g} / 3 \mathrm{mg}$; Yasmin $^{\circledR}$, Bayer HealthCare Pharmaceuticals) for 13 cycles.

\section{Clinical profiles}

\section{Pharmacodynamic effects}

The pharmacodynamic effects of $\mathrm{E}_{2} \mathrm{~V} / \mathrm{CPA}, \mathrm{E}_{2} \mathrm{~V} / \mathrm{DNG}$, and $\mathrm{E}_{2} / \mathrm{NOMAC}$, as well as the individual progestin components (CPA, DNG, and NOMAC, respectively), have been well documented. ${ }^{26,34,40-43}$ In essence, the main contraceptive effects of these combined formulations are due to the progestin component; this is also the case with other COCs containing EE. ${ }^{44}$

CPA $1 \mathrm{mg}$ daily appears sufficient to inhibit ovulation. ${ }^{43}$ A dose-ranging study of CPA $(0.125-1.00 \mathrm{mg}$ daily) in healthy women aged $20-28$ years $(n=12)$ showed that CPA $1 \mathrm{mg}$ inhibited ovulation (as determined by daily measurements of luteinizing hormone, follicle-stimulating hormone, $E_{2}$, and progesterone) in all women assessed $(n=5){ }^{43}$ Concomitant effects of CPA on the endometrium and cervical mucus were not reported in this study.

The ovulation-inhibiting effects of DNG were assessed in a dose-ranging $(0.5 \mathrm{mg}-3 \mathrm{mg}$ DNG daily) study in healthy women aged $18-35$ years $(n=102)$ using the Hoogland score, which determines ovarian activity based on largest follicular size and highest serum hormone levels. ${ }^{42}$ Dose-dependent ovulation-inhibiting effects were observed across the doses tested. Ovulation was suppressed in all women taking $2 \mathrm{mg}$ $(n=20)$ or $3 \mathrm{mg}(\mathrm{n}=23)$ of DNG daily. In addition, endometrial thickness was reduced compared with pretreatment. DNG also induced moderate suppression of endogenous $E_{2}$ production.

The contraceptive effects of NOMAC have also been assessed in a dose-ranging (1.25-5 mg NOMAC daily) study in 13 healthy women. In this study, pituitary-ovarian function was determined by measuring $\mathrm{E}_{2}$, follicle-stimulating hormone, and luteinizing hormone levels. ${ }^{45}$ Ovulation was inhibited in all women across the doses of NOMAC. In a separate study of 16 normally cycling women assessing the effects of NOMAC (2.5 mg or $5 \mathrm{mg}$ daily) on mid-cycle cervical mucus, the changes observed were similar to those induced by progesterone during the luteal phase. ${ }^{46}$ In a more recent study, $2.5 \mathrm{mg}$ of NOMAC was again shown to inhibit ovulation and decrease cervical mucus scores (ie, indicative of increased hostility to sperm penetration) in healthy women aged $18-35$ years $(n=9) .{ }^{40}$ These data support cervical mucus inhibition as a secondary contraceptive mechanism.

The approved formulations of $\mathrm{E}_{2} \mathrm{~V} / \mathrm{CPA}, \mathrm{E}_{2} \mathrm{~V} / \mathrm{DNG}$, and $\mathrm{E}_{2} / \mathrm{NOMAC}$ all consistently inhibit ovulation in $\geq 95 \%$ of women. ${ }^{26,34,40,41,47}$ However, studies with $\mathrm{E}_{2} \mathrm{~V} / \mathrm{CPA}$ were performed in small samples of women with a mean age of 39 (range 30-49) years, and as such may overestimate the rate of ovulation inhibition in "more fertile" younger women..$^{34,41}$ In addition, the contraceptive effects of $\mathrm{E}_{2} \mathrm{~V} / \mathrm{CPA}$ achieved through alteration in cervical mucus and the endometrium have not, to our knowledge, been reported. $\mathrm{E}_{2} \mathrm{~V} / \mathrm{DNG}$ has been shown to have suppressive effects on endometrial growth and cervical mucus as assessed by transvaginal ultrasound in healthy women aged $18-35$ years $(n=100)$; mean 
maximal endometrial thickness decreased from $10.1 \mathrm{~mm}$ at baseline to $6.5 \mathrm{~mm}$ during cycle 3. Although treatment was associated with a reduction in the ultrasound appearance of cervical mucus, the quality of mucus was not assessed. ${ }^{48}$ Similar changes in cervical mucus and the endometrium were observed with $\mathrm{E}_{2} / \mathrm{NOMAC}$ in healthy women aged $18-35$ years $(n=32)$; mean maximum endometrial thickness was reduced from $9.9 \mathrm{~mm}$ at screening to $4.9 \mathrm{~mm}$ in cycle 6 . In this study, cervical mucus, assessed using the Insler cervical mucus score, decreased from a mean maximum of 8.9 at screening to 2.3 during the first treatment cycle (with lower scores indicating poor likelihood of sperm penetration). ${ }^{47}$

\section{Contraceptive efficacy}

The approved $\mathrm{E}_{2} \mathrm{~V} / \mathrm{CPA}, \mathrm{E}_{2} \mathrm{~V} / \mathrm{DNG}$, and $\mathrm{E}_{2} / \mathrm{NOMAC}$ formulations appear to have similar contraceptive efficacy profiles (Table 1)..$^{30,34-36,39}$ The net pregnancy rate with $\mathrm{E}_{2} \mathrm{~V} /$ CPA was reported to be $0.4 \%$ over 12 months in Finnish women ( $n=288$ ) aged 30-49 years; one pregnancy occurred in 2,800 cycles of exposure, equating to a Pearl Index of $0.46 .{ }^{34}$ Again this may be an overestimation of the contraceptive efficacy of $E_{2} \mathrm{~V} / \mathrm{CPA}$ in younger more fertile women. In addition, this lone study would be insufficient to meet current recommendations for regulatory approval of a new hormonal contraceptive in Europe ("for any new contraceptive, at least 400 women should have completed one year of treatment"). ${ }^{49}$

The contraceptive efficacy of $\mathrm{E}_{2} \mathrm{~V} / \mathrm{DNG}$ was established in two open-label, noncomparative studies, one conducted in Europe and the other in North America, in over 1,850 women aged 18-50 years. ${ }^{35,36}$ In the European study (conducted in Austria, Germany, and Spain), the Pearl Index at 20 cycles of treatment was reported to be 0.73 in women aged $18-50$ years and 0.94 in women aged $18-35$ years $(n=998) .{ }^{35}$ The second study conducted in North America recruited women aged 18-35 years $(n=490)$ and reported a Pearl Index of 1.64 at one year; however, this study was not sufficiently powered for a stand-alone contraceptive efficacy calculation.

The contraceptive efficacy of $\mathrm{E}_{2}$ /NOMAC was established in two randomized, open-label, comparative studies (compared with EE $30 \mu \mathrm{g} / \mathrm{DRSP} 3 \mathrm{mg}$ [Yasmin]), one conducted in Europe, Asia, and Australia, ${ }^{30}$ and the other in the US, Canada, Argentina, Brazil, Chile, and Mexico, ${ }^{39}$ in over 3,250 women aged 18-50 years. The study conducted in Europe, Asia, and Australia reported a Pearl Index of 0.31 in women aged $18-50$ years, and a Pearl Index of 0.38 in women aged $18-35$ years $(n=1,315)$. The other $\mathrm{E}_{2} / \mathrm{NOMAC}$ efficacy study reported a Pearl Index at one year of 1.13 in women aged 18-50 years, with a corresponding Pearl Index of 1.27 in women aged $18-35$ years $(n=1,375)$.

Of note, the Pearl indices reported at one year from the $\mathrm{E}_{2} \mathrm{~V} / \mathrm{DNG}$ and $\mathrm{E}_{2} / \mathrm{NOMAC}$ studies that included study centers in the US were slightly higher than for the similar studies conducted elsewhere. This is a well recognized phenomenon in contraceptive research, and may, in part, be due to differences in compliance rates and/or recruitment practices. ${ }^{50}$ Indeed, residential poverty level, an indirect measure of individual income, was shown to be the strongest predictor of noncompliance in a US oral contraceptive clinical trial. ${ }^{51}$ Nonetheless, the one-year Pearl indices for the approved $\mathrm{E}_{2}$-containing oral contraceptives are consistent with those reported for recently approved low-dose EE-containing formulations (Pearl indices $0-1.6) .^{50}$

\section{Bleeding profile}

A direct comparison of bleeding profile between oral contraceptive formulations, especially by cycle, is difficult due to the lack of uniform definitions and results across studies. ${ }^{52}$

Table I Summary of published studies reporting contraceptive efficacy of estradiol-containing oral contraceptives

\begin{tabular}{|c|c|c|c|c|c|c|c|c|}
\hline Formulation & Study location & $\begin{array}{l}\text { Treatment } \\
\text { duration }\end{array}$ & $\begin{array}{l}\text { Age group, } \\
\text { years }\end{array}$ & $\mathbf{n}$ & Exposure & Pregnancies (n) & $\begin{array}{l}\text { Pearl } \\
\text { Index }\end{array}$ & $\begin{array}{l}\text { Upper } \\
95 \% \mathrm{Cl}\end{array}$ \\
\hline $\mathrm{E}_{2} \mathrm{~V} / \mathrm{CPA}^{34}$ & Finland & I year & $30-49$ & 288 & 2,800 cycles & $\mathrm{I}$ & 0.46 & \\
\hline \multirow{3}{*}{$\mathrm{E}_{2} \mathrm{~V} / \mathrm{DNG}^{35}$} & Austria, & 20 cycles & $18-50$ & $\mathrm{I}, 377$ & 23,368 cycles & 13 & 0.73 & 1.24 \\
\hline & Germany, & & $18-35$ & 998 & 16,608 cycles & 12 & 0.94 & 1.65 \\
\hline & Spain & & $>35-50$ & 379 & 6,760 cycles & I & 0.19 & \\
\hline $\mathrm{E}_{2} \mathrm{~V} / \mathrm{DNG}^{36}$ & US, Canada & I year & $18-35$ & 490 & 3,969 cycles & 5 & 1.64 & 3.82 \\
\hline \multirow[t]{3}{*}{$\mathrm{E}_{2} / \mathrm{NOMAC}^{30}$} & Europe, Asia, & I year & $18-50$ & $\mathrm{I}, 587$ & I,293 woman-years & 4 & 0.31 & 0.79 \\
\hline & Australia & & $18-35$ & 1,315 & I,058 woman-years & 4 & 0.38 & 0.97 \\
\hline & & & $>35-50$ & 272 & 235 woman-years & 0 & 0 & \\
\hline \multirow[t]{3}{*}{$\mathrm{E}_{2} / \mathrm{NOMAC}^{39}$} & US, Canada, & I year & $18-50$ & 1,634 & I, I 46 woman-years & 13 & 1.13 & 1.94 \\
\hline & Argentina, Brazil, & & $18-35$ & $\mathrm{I}, 375$ & 946 woman-years & 12 & 1.27 & 2.22 \\
\hline & Chile, Mexico & & $>35-50$ & 259 & 235 woman-years & I & 0.43 & \\
\hline
\end{tabular}

Abbreviations: $\mathrm{Cl}$, confidence interval; $\mathrm{CPA}$, cyproterone acetate; $\mathrm{E}_{2} \mathrm{~V}$, estradiol valerate; $\mathrm{DNG}$, dienogest; NOMAC, nomegestrol acetate; $\mathrm{E}_{2}$, estradiol. 
Although the World Health Organization has made recommendations for the analysis of menstrual patterns, these have not been uniformly adopted. Nonetheless, irrespective of definitions used, studies that assessed bleeding profiles associated with $\mathrm{E}_{2} \mathrm{~V} / \mathrm{CPA}, \mathrm{E}_{2} \mathrm{~V} / \mathrm{DNG}$, and $\mathrm{E}_{2} / \mathrm{NOMAC}$ consistently suggest that these oral contraceptives are associated with shorter, lighter bleeding versus comparator EE-containing pills or baseline. ${ }^{27,30,34,36,39,41}$

Table 2 summarizes the number of uterine bleeding days using 90-day and 91-day reference periods observed in the randomized controlled trials with $\mathrm{E}_{2} \mathrm{~V} / \mathrm{DNG}$ and $\mathrm{E}_{2} / \mathrm{NOMAC}$ compared with EE/levonorgestrel (EE $20 \mu \mathrm{g} / \mathrm{LNG} 100 \mu \mathrm{g}$, Miranova $^{\circledR}$, Bayer HealthCare Pharmaceuticals) and EE/ DRSP (Yasmin), respectively. ${ }^{27,30,39}$ The study with $\mathrm{E}_{2} \mathrm{~V} /$ DNG and EE/LNG was conducted over seven 28-day cycles in centers across Germany, the Czech Republic, and France, and reported uterine bleeding data from 399 women aged 18-50 years in both treatment groups. ${ }^{27}$ These studies demonstrated statistically significant and/or clinically meaningful reductions in bleeding/spotting days with $\mathrm{E}_{2} \mathrm{~V} /$ DNG and $\mathrm{E}_{2} / \mathrm{NOMAC}$ compared with the comparator EE-based oral contraceptives. ${ }^{27,30,39}$ There are no available bleeding data with $\mathrm{E}_{2} \mathrm{~V} / \mathrm{CPA}$ where the data are reported by reference period.

The data reported by cycle with both $\mathrm{E}_{2} \mathrm{~V} / \mathrm{DNG}$ and $\mathrm{E}_{2} / \mathrm{NOMAC}$ are also consistent with reduced bleeding (or an absence of bleeding) relative to the comparator EEbased formulations. For example, the rate of absence of withdrawal bleeding (mean over cycles $1-7$ ) was $19.4 \%$ (range 16.8\%-22.3\%) in women treated with $\mathrm{E}_{2} \mathrm{~V} / \mathrm{DNG}$ compared with $7.7 \%$ (range $6.2 \%-10.5 \%$ ) in women treated with EE/LNG. ${ }^{27}$ In the open-label North American $\mathrm{E}_{2} \mathrm{~V} / \mathrm{DNG}$ study, the rate of absent withdrawal bleeding occurred in a mean $23.5 \%$ of women through cycles $1-12$ (range $17 \%$ and $32 \%$ ). ${ }^{36}$ For $\mathrm{E}_{2} / \mathrm{NOMAC}$, in the study conducted in Europe, Asia, and Australia, 30\% of women had at least one absence of withdrawal bleeding during cycles 2-4. Moreover, a progressive increase in the incidence of absent withdrawal bleeding from $22 \%$ to $31 \%$ occurred in cycles 4-12, indicating a tendency towards absent withdrawal bleeding with continued use. ${ }^{30}$ In the comparator EE/DRSP formulation group, the incidence of absent withdrawal bleeding was relatively stable, ranging from $3 \%$ to $6 \%$. A similar trend towards absent withdrawal bleeding with continued use (approximately 18\%-34\%) was also observed with $\mathrm{E}_{2} / \mathrm{NOMAC}$, but not with EE/DRSP (approximately 4\%-9\%), in the study conducted in North and South America. ${ }^{39}$

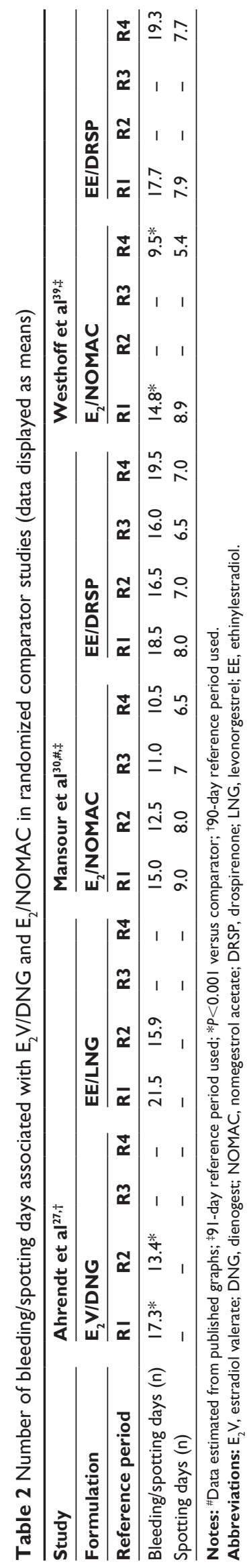


Intracyclic bleeding was reported to occur in approximately $14 \%$ of women receiving $\mathrm{E}_{2} \mathrm{~V} / \mathrm{DNG}$ (ranging from $10.5 \%$ to $18.6 \%$ ) over cycles $1-7$ compared with approximately $12 \%$ of women receiving the comparator EE/LNG formulation (ranging from $9.9 \%$ to $17.1 \%$ ). ${ }^{27}$ In the openlabel, North American $E_{2}$ V/DNG study, intracyclic bleeding ranged from $28.8 \%$ to $11.2 \%$ during cycles $2-13$, with the data generally indicative of a tendency to less intracyclic bleeding with continued use. ${ }^{36}$ For $\mathrm{E}_{2} / \mathrm{NOMAC}$, in the study conducted in Europe, Asia, and Australia, intracyclic bleeding progressively decreased with continued $\mathrm{E}_{2} / \mathrm{NOMAC}$ use from about $34 \%$ to $14 \%$ (through cycles $1-13$ ); a similar trend was observed with the comparator EE/DRSP (28\% to $13 \%$ through cycles $1-13) .{ }^{30} \mathrm{~A}$ similar trend towards progressively decreased intracyclic bleeding with continued $\mathrm{E}_{2} / \mathrm{NOMAC}$ use (from about $31 \%$ to $16 \%$ through cycles 1-13) was also observed in the study conducted in North and South America. ${ }^{39}$

The overall bleeding profile associated with $\mathrm{E}_{2} \mathrm{~V} / \mathrm{CPA}$ is less well characterized compared with the other two approved $\mathrm{E}_{2}$-based formulations. In the pivotal, open-label, noncomparative study in Finnish women, intracyclic bleeding occurred in $33 \%$ of $\mathrm{E}_{2} \mathrm{~V} / \mathrm{CPA}$ users (mainly spotting) at 3 months, decreasing to $22 \%$ at 6 months and $24 \%$ at 12 months. ${ }^{34}$ Much lower rates of intracyclic bleeding were reported with $\mathrm{E}_{2} \mathrm{~V} / \mathrm{CPA}(\mathrm{n}=26)$ in a second study $(0 \%-15 \%)$, which was a randomized double-blind trial including biphasic $\mathrm{E}_{2} \mathrm{~V} /$ norethisterone, but it is not clear from the report whether the incidence of spotting $(20 \%-40 \%)$ included intracyclic bleeding. ${ }^{41}$ Using the comparator $\mathrm{E}_{2} \mathrm{~V} /$ norethisterone $(\mathrm{n}=24)$, intracyclic bleeding occurred in $6 \%-42 \%$ of women (highest during the second cycle). Absent bleeding with $\mathrm{E}_{2} \mathrm{~V} / \mathrm{CPA}$ ranged between $5 \%$ and $19 \%$ (versus $6 \%-25 \%$ in the comparator group). The mean number of bleeding/spotting days per cycle decreased from $5.0 \pm 1$ days in the pretreatment cycle to $3.8 \pm 3.3$ days by cycle 12 . In contrast, the number of bleeding/spotting days per cycle remained relatively stable with the comparator $\mathrm{E}_{2} \mathrm{~V}$ /norethisterone (between $4.9 \pm 1.2$ days to $5.2 \pm 2.5$ days).

\section{Hemostasis, lipid, and carbohydrate metabolism, and other parameters}

Generally, $\mathrm{E}_{2}$ and $\mathrm{E}_{2} \mathrm{~V}$ at equimolar doses are expected to have similar influences on hemostasis, lipids, and carbohydrate metabolism parameters, but less than those observed with EE. However, surrogate indices of hemostasis, lipids, and carbohydrate metabolism, or any other surrogate marker, cannot be translated into meaningful clinical outcomes, and the risk of cardiovascular events in users of oral contraceptives containing $\mathrm{E}_{2}$ or $\mathrm{E}_{2} \mathrm{~V}$ needs to be established in large-scale, post-marketing, prospective, Phase IV cohort studies. Indeed, two large international active surveillance studies, ie, the International Active Surveillance Study-Safety of Contraceptives: Role of Estrogens (INAS SCORE) ${ }^{53}$ and the Choice of estrogen and long-term investigation of nomegestrol acetate-International Active Surveillance Study (INAS-CELINA) ${ }^{54}$ are currently underway to investigate the occurrence of adverse cardiovascular events within a 5-year period in $\mathrm{COC}$ users (including $\mathrm{E}_{2} \mathrm{~V} / \mathrm{DNG}$ and $\mathrm{E}_{2} / \mathrm{NOMAC}$, respectively). To the best of our knowledge, no such active surveillance studies have been undertaken or are planned for the $\mathrm{E}_{2} \mathrm{~V} / \mathrm{CPA}$ oral contraceptive.

Large prospective cohort studies have the best ability to assess uncommon adverse outcomes like venous thrombosis, because their design allows for collection of baseline information on important confounders, such as obesity and age. ${ }^{5-57}$ Recently published database studies have suggested that oral contraceptives containing CPA, desogestrel, or DRSP in combination with EE are associated with an elevated risk of venous thrombosis compared with LNG pills. ${ }^{58,59}$ However, a large prospective Phase IV study similar in design to the INAS-CELINA and INAS-SCORE studies did not demonstrate an increase in risk for deep vein thrombosis with these progestins. ${ }^{60}$

$\mathrm{E}_{2} \mathrm{~V} / \mathrm{CPA}$ appears to have minimal influence on hemostatic parameters over three cycles. ${ }^{41}$ Both total cholesterol and high-density lipoprotein cholesterol were reported to decrease (by $9 \%$ and $5 \%$, respectively) relative to baseline over 13 cycles in one study, ${ }^{41}$ but no significant changes were reported in total cholesterol or high-density lipoprotein cholesterol in the pivotal Finnish study. ${ }^{34}$ In the latter study, serum triglyceride levels increased $>20 \%$ over 13 cycles. ${ }^{34}$

The impact of $\mathrm{E}_{2} \mathrm{~V} / \mathrm{DNG}$ and $\mathrm{E}_{2} / \mathrm{NOMAC}$ on hemostatic and lipid parameters relative to EE-based oral contraceptive comparators is summarized in Table 3; both formulations appear to have less influence on these parameters than the EE-based formulations. ${ }^{61-64}$ However, it is important to keep in mind that none of these potential surrogate markers of venous thromboembolism risk have ever been validated. Estrogens influence both thrombotic and fibrinolytic pathways, and the net effect on hemostasis is difficult to predict. ${ }^{65}$ High-density lipoprotein cholesterol and low-density lipoprotein cholesterol were reported to increase and decrease, respectively, with both $\mathrm{E}_{2} \mathrm{~V} / \mathrm{DNG}$ and $\mathrm{E}_{2} / \mathrm{NOMAC}$ during up to seven cycles of treatment. The overall changes relative to baseline in these parameters were $<10 \%$ for $\mathrm{E}_{2} \mathrm{~V} / \mathrm{DNG}$ 
Table 3 Changes from baseline in hemostatic, lipid, and carbohydrate metabolism indices

\begin{tabular}{|c|c|c|c|c|c|c|c|c|}
\hline \multirow[b]{2}{*}{ Formulation } & \multicolumn{2}{|c|}{$\begin{array}{l}\text { Junge et } a^{61, \#} \\
\text { (7 cycles) }\end{array}$} & \multicolumn{2}{|c|}{$\begin{array}{l}\text { Klipping et } a^{\left.\right|^{62, \#}} \\
\text { ( } 3 \text { cycles) }\end{array}$} & \multicolumn{2}{|l|}{$\begin{array}{l}\text { Agren et } a l^{63} \\
(6 \text { cycles })\end{array}$} & \multicolumn{2}{|c|}{$\begin{array}{l}\text { Gaussem et } a^{1^{64}} \\
\text { ( } 3 \text { cycles) }\end{array}$} \\
\hline & $E_{2} V / D N G$ & EE/LNG & $E_{2} V / D N G$ & EE/LNG & $E_{2} /$ NOMAC & EE/LNG & $E_{2} /$ NOMAC & EE/LNG \\
\hline \multicolumn{9}{|l|}{ Hemostasis } \\
\hline $\begin{array}{l}\text { Prothrombin } \\
\text { fragment I + } 2\end{array}$ & $=$ & +++ & $=$ & ++ & $=$ & + & $=$ & + \\
\hline D-dimer & $=$ & ++ & ++ & +++ & $=$ & $=$ & -- & + \\
\hline Fibrinogen & $=$ & ++ & + & ++ & NR & NR & $=$ & + \\
\hline Factor VII activity & + & ++ & $=$ & $=$ & $=^{\Phi}$ & $+^{\Phi}$ & NR & NR \\
\hline Factor VIII activity & $=$ & $=$ & $=$ & $=$ & $=$ & $=$ & $=$ & $=$ \\
\hline $\begin{array}{l}\text { Antithrombin III } \\
\text { activity }\end{array}$ & $=$ & $=$ & $=$ & $=$ & $=$ & $=$ & $=$ & $=$ \\
\hline Protein $C$ activity & $=$ & + & $=$ & $=$ & $=^{\ddagger}$ & $=^{\ddagger}$ & NR & NR \\
\hline $\begin{array}{l}\text { APC sensitivity } \\
\text { ratio }(\mathrm{aPTT})\end{array}$ & $=$ & $=$ & $=$ & $=$ & $=$ & $=$ & NR & NR \\
\hline APC sensitivity ratio & NR & NR & $={ }^{*}$ & $++^{*}$ & +++ & +++ & $++^{*}$ & $+t^{*}$ \\
\hline PAI-I antigen & - & -- & NR & NR & NR & NR & -- & --- \\
\hline PAI-I activity & $=$ & $=$ & NR & NR & NR & NR & NR & NR \\
\hline \multicolumn{9}{|l|}{ Lipid } \\
\hline Total cholesterol & $=$ & $=$ & NR & NR & $=$ & $=$ & NR & NR \\
\hline High-density lipoprotein & $=$ & $=$ & NR & NR & $=$ & - & NR & NR \\
\hline Low-density lipoprotein & $=$ & $=$ & NR & NR & $=$ & $=$ & NR & NR \\
\hline Triglycerides & ++ & ++ & NR & NR & $=$ & + & NR & NR \\
\hline
\end{tabular}

Notes: \#Intraindividual change; ${ }^{\sharp} \mathrm{APC}-\mathrm{r}$, Rosing’s activated protein $\mathrm{C}$ resistance normalized ratio; ${ }^{\Phi}$ factor $\mathrm{VI}$ Ia or VIlc; $=$, no change $(<\mathrm{I} 0 \%$ change); + , $\geq 10 \%$ increase; ,$- \geq 10 \%$ decrease;,$++ \geq 20 \%$ increase;,$-- \geq 20 \%$ decrease;,$+++ \geq 50 \%$ increase;,$--- \geq 50 \%$ decrease.

Abbreviations: APC, activated protein C; aPTT, activated partial thromboplastin time; NR, not reported; PAI-I, plasminogen activator inhibitor type I; $\mathrm{E}_{2} \mathrm{~V}$, estradiol valerate; DNG, dienogest; NOMAC, nomegestrol acetate; EE, ethinylestradiol; LNG, levonorgestrel.

and $<2 \%$ for $\mathrm{E}_{2} / \mathrm{NOMAC}$. ${ }^{61,63}$ Total cholesterol increased with both $\mathrm{E}_{2} \mathrm{~V} / \mathrm{DNG}$ and $\mathrm{E}_{2} / \mathrm{NOMAC}$, but by $\leq 5 \%$ relative to baseline. Mean increases in endogenous thrombin potential-based activated protein $\mathrm{C}$ sensitivity ratios from baseline to cycle 3 were significantly lower with $\mathrm{E}_{2} \mathrm{~V} / \mathrm{DNG}$ (0.09 versus $0.56, P<0.001)$ and $\mathrm{E}_{2} / \mathrm{NOMAC}(0.20$ versus $0.46, P<0.01)$ than with EE/LNG (EE $30 \mu \mathrm{g} / \mathrm{LNG}$ $150 \mu \mathrm{g}$; Microgynon ${ }^{\circledR}$, Bayer HealthCare Pharmaceuticals) or EE/LNG (EE $20 \mu \mathrm{g} / \mathrm{LNG} 100 \mu \mathrm{g}$; Miranova) comparators, respectively. ${ }^{62,64}$ Additionally, insulin and glucose remained relatively unaffected by $\mathrm{E}_{2} \mathrm{~V} / \mathrm{DNG}$ and $\mathrm{E}_{2} / \mathrm{NOMAC}$ during oral glucose tolerance tests. ${ }^{61,63}$

The available data across four separate randomized trials seem to suggest that increases in sex hormone binding globulin (SHBG) with both $\mathrm{E}_{2} \mathrm{~V} / \mathrm{DNG}$ and $\mathrm{E}_{2} / \mathrm{NOMAC}$ are more or less in the same range, ${ }^{61-64}$ however, increases in SHBG with the EE-based comparators in these studies were more inconsistent. In general, it would be expected that $\mathrm{EE}$ increases SHBG levels to a greater extent than $\mathrm{E}_{2}{ }^{10}$ In COCs, the extent of an EE-induced (or $\mathrm{E}_{2}$-induced) SHBG increase may be attenuated by inclusion of a progestin with androgenic activity. ${ }^{10}$ Of note, the progestins used in the three approved $\mathrm{E}_{2}$-containing oral contraceptives do not have any androgenic activity, ${ }^{66}$ and as such are not expected to attenuate the limited estrogen-induced SHBG increase with the $\mathrm{E}_{2}$-containing oral contraceptives.

\section{Safety and tolerability}

The relevance of nonspecific adverse events with oral contraceptives reported outside randomized placebo-controlled trials has been questioned because the limited level I evidence suggests that these nonspecific events may not occur significantly more often with oral contraceptives and that they may simply reflect their background prevalence in the population. ${ }^{67}$ With this in mind, the adverse events reported in the $\mathrm{E}_{2} \mathrm{~V} / \mathrm{CPA}, \mathrm{E}_{2} \mathrm{~V} /$ $\mathrm{DNG}$, or $\mathrm{E}_{2} / \mathrm{NOMAC}$ studies with $>250$ patients receiving one of the three oral contraceptives that were judged to be treatment-related were in general typical of those reported with EE-based oral contraceptives. ${ }^{27,30,35,36,39}$ Results from the randomized comparator studies of $\mathrm{E}_{2} \mathrm{~V} / \mathrm{DNG}$ and $\mathrm{E}_{2} /$ NOMAC show a similar distribution of adverse events. In the only placebo-controlled studies, where $\mathrm{E}_{2} \mathrm{~V} / \mathrm{DNG}$ was used to manage heavy menstrual bleeding in North America and in Europe/Australia, breast pain and irregular bleeding were more common in women receiving $\mathrm{E}_{2} \mathrm{~V} / \mathrm{DNG}$, while headache was more commonly reported with placebo (Table 4). ${ }^{37,38}$ For $\mathrm{E}_{2} \mathrm{~V} /$ CPA $(n=288)$ in the Finnish study, adverse events reported after 6 months included breast tenderness $(9.4 \%)$, edema $(8.5 \%)$, 
Table 4 Common adverse events (in alphabetical order) in subjects treated with estradiol valerate/dienogest or placebo in two randomized trials

\begin{tabular}{lll}
\hline Adverse events, $\mathbf{n}(\%)$ & $\mathbf{E}_{\mathbf{2}}$ V/DNG $(\mathbf{n}=\mathbf{2 6 4})$ & Placebo $(\mathbf{n}=\mathbf{I 4 7})$ \\
\hline Subject-reported events & & \\
Acne & II $(4.2)$ & $3(2.0)$ \\
Back pain & $6(2.3)$ & $7(4.8)$ \\
Breast pain & $13(4.9)$ & $0(0.0)$ \\
Breast tenderness & $10(3.8)$ & $4(3.7)$ \\
Headache & $26(9.8)$ & $21(14.2)$ \\
Metrorrhagia & $14(5.3)$ & $1(0.7)$ \\
Nasopharyngitis & $21(8.0)$ & $4(6.8)$ \\
Nausea & $13(4.9)$ & $7(4.7)$ \\
Vomiting & $5(1.9)$ & $6(4.1)$ \\
\hline
\end{tabular}

Notes: Adapted with permission from Fraser IS, Römer T, Parke S, et al. Effective treatment of heavy and/or prolonged menstrual bleeding with an oral contraceptive containing estradiol valerate and dienogest: a randomized, double-blind Phase III trial. Hum Reprod. 201 1;26:2698-2708. ${ }^{37}$ Adapted with permission from Lippincott Williams \& Wilkins/Wolters Kluwer Health: Obstet Gynecol. Jensen JT, Parke S, Mellinger U, Machlitt A, Fraser IS. Effective treatment of heavy menstrual bleeding with estradiol valerate and dienogest: a randomized controlled trial. 201 I; I 17:777-787. ${ }^{38}$

Copyright (c) 201I. Promotional and commercial use of the material in print, digita or mobile device format is prohibited without the permission from the publisher Lippincott Williams \& Wilkins. Please contact journalpermissions@lww.com for further information.

Abbreviations: $E_{2} V$, estradiol valerate; DNG, dienogest.

headache (6.6\%), and depression (4.2\%), decreasing to $7.7 \%$, $5.5 \%, 4.4 \%$, and $2.7 \%$, respectively, by 12 months. ${ }^{34}$

Discontinuations due to adverse events during up to 20 cycles of treatment with $\mathrm{E}_{2} \mathrm{~V} / \mathrm{DNG}$ were reported to be up to $14 \%, 27,35,36$ with discontinuations due to bleeding problems ranging up to $5 \%$ over the first year of use. ${ }^{36}$ Similar discontinuation rates were documented for $\mathrm{E}_{2} / \mathrm{NOMAC}$, with up to $18 \%$ discontinuing due to adverse events over one year and up to $5 \%$ due to bleeding problems. ${ }^{30,39}$ For E V/CPA, 16\% of women discontinued due to adverse events typically related to hormone use ("edema, breast tenderness, headache, weight change, and mood changes") over one year and $9 \%$ due to menstrual problems. ${ }^{34}$

The effects of $\mathrm{E}_{2} / \mathrm{NOMAC}(\mathrm{n}=56)$ on bone mineral density were compared with those of EE/LNG (EE $30 \mu \mathrm{g} / \mathrm{LNG}$ $150 \mu \mathrm{g}$; Microgynon, $\mathrm{n}=54$ ) in women aged 20-35 years over 2 years in a randomized controlled trial. ${ }^{68}$ No clinically relevant effects on bone mineral density were observed during this time with $\mathrm{E}_{2} / \mathrm{NOMAC}$ or with the $\mathrm{EE} / \mathrm{LNG}$ oral contraceptive comparator. In the absence of data on the effects of $\mathrm{E}_{2} \mathrm{~V} / \mathrm{DNG}$ or $\mathrm{E}_{2} \mathrm{VCPA}$ on bone mineral density, it might be postulated that because similar doses of $\mathrm{E}_{2}$ are used relative to $\mathrm{E}_{2} / \mathrm{NOMAC}$, the effects on bone density would be similar.

\section{Other indications and benefits}

The choice between the $\mathrm{E}_{2} \mathrm{~V} / \mathrm{CPA}, \mathrm{E}_{2} \mathrm{~V} / \mathrm{DNG}$, and $\mathrm{E}_{2} / \mathrm{NOMAC}$ formulations is currently restricted by regional availability; so far, only Finnish women have access to all three $\mathrm{E}_{2}$-based formulations. Elsewhere, women have either the option of $\mathrm{E}_{2} \mathrm{~V} / \mathrm{DNG}$ or $\mathrm{E}_{2} / \mathrm{NOMAC}$ (eg, Europe) or $\mathrm{E}_{2} \mathrm{~V} / \mathrm{DNG}$ (eg, the $\mathrm{US}$ ) alone as the only available $\mathrm{E}_{2}$-based formulations.

Several studies have been conducted with $\mathrm{E}_{2} \mathrm{~V} / \mathrm{DNG}$ to assess additional health benefits. No studies assessing additional health benefits associated with the other two $\mathrm{E}_{2}$-based formulations have been published. $\mathrm{E}_{2} \mathrm{~V} / \mathrm{DNG}$ has been shown to profoundly reduce menstrual blood loss in women with objectively confirmed heavy menstrual bleeding without organic pathology in two randomized, placebocontrolled, double-blind studies, one conducted in the US and Canada and the other in Europe and Australia. ${ }^{37,38}$ These studies led to the approval of $\mathrm{E}_{2} \mathrm{~V} / \mathrm{DNG}$ for the treatment of heavy menstrual bleeding, a unique indication for this oral contraceptive formulation. The effect is rapid, with the greatest reduction in menstrual blood loss achieved by the first withdrawal bleed after treatment initiation and maintained with no loss of effect with continued treatment. Moreover, the observed reduction in menstrual blood loss with $\mathrm{E}_{2} \mathrm{~V} / \mathrm{DNG}$ (median $88 \%$ reduction after seven cycles of treatment) appears to approach that achieved with the LNG-releasing intrauterine system. ${ }^{69}$ Overall, 64\% of women with excessive menstrual blood loss receiving $\mathrm{E}_{2} \mathrm{~V} /$ DNG met the study criteria for treatment success (defined as menstrual blood loss $<80 \mathrm{~mL}$ and a $\geq 50 \%$ reduction from baseline) compared with only $12 \%$ with placebo. ${ }^{70}$ Secondary endpoints in the two randomized studies included the impact of treatment with $\mathrm{E}_{2} \mathrm{~V} / \mathrm{DNG}$ on heavy menstrual bleeding-related impairment of work productivity (presenteeism) and activities of daily living. ${ }^{71,72}$ These studies showed that $\mathrm{E}_{2} \mathrm{~V} / \mathrm{DNG}$ had a consistent positive impact on work productivity and activities of daily living in women with heavy menstrual bleeding, and that these improvements could be translated into a reduction in the monetary burden associated with this condition.

Two more randomized, double-blind, active-controlled studies, one conducted in North America and the other in Western Europe, Thailand, Australia, and Mexico, were undertaken to assess the effect of $\mathrm{E}_{2} \mathrm{~V} / \mathrm{DNG}$ on hormone withdrawal-associated symptoms (principally headache or pelvic pain) in women ( $n=414$, across both studies) who experienced these symptoms with other COCs taken in the traditional $21 / 7$ regimen. ${ }^{73,74}$ Switching to $\mathrm{E}_{2} \mathrm{~V} / \mathrm{DNG}$ was shown to reduce the severity of these symptoms to a greater extent than switching to comparator triphasic EE/norgestimate (Ortho Tri-Cyclen ${ }^{\circledR}$ Lo, Ortho-McNeil-Janssen Pharmaceuticals Inc, Raritan, NJ, USA; n=204) or a monophasic EE/LNG (Microgynon; $n=218$ ). 
A multicenter, double-blind, randomized study was conducted in Europe and Asia/Pacific to determine the effect of $E_{2} V / D N G(n=92)$ on oral contraceptive-related sexual dysfunction using EE/LNG (Microgynon, $n=99$ ) as a comparator. ${ }^{75}$ Among women reporting baseline sexual dysfunction while using an oral contraceptive, switching to either $\mathrm{E}_{2} \mathrm{~V} / \mathrm{DNG}$ or $\mathrm{EE} / \mathrm{LNG}$ resulted in similar improvements in desire and arousal, a reduction in associated distress, and decreased vaginal symptoms. A study from Italy also suggested some benefit on sexual function with $\mathrm{E}_{2} \mathrm{~V} / \mathrm{DNG}$ $(n=57)$, but the open-label noncomparative nature of this study provides no reference for the observed changes, making it impossible to draw conclusions from these results. ${ }^{76}$

\section{Conclusion}

In summary, $\mathrm{E}_{2} \mathrm{~V} / \mathrm{DNG}, \mathrm{E}_{2} / \mathrm{NOMAC}$, and $\mathrm{E}_{2} \mathrm{~V} / \mathrm{CPA}$ are all effective oral contraceptives. The contraceptive effectiveness of $\mathrm{E}_{2} \mathrm{~V} / \mathrm{CPA}$ was, however, assessed in women with a mean age of 39 years, and as such may not be directly generalizable to younger more fertile women. Although direct comparability between the studies is difficult, the available data suggest that $\mathrm{E}_{2} \mathrm{~V} / \mathrm{DNG}$ and $\mathrm{E}_{2} / \mathrm{NOMAC}$ may have better bleeding profiles than $\mathrm{E}_{2} \mathrm{~V} / \mathrm{CPA}$. Currently, $\mathrm{E}_{2} \mathrm{~V} / \mathrm{DNG}$ is the only oral contraceptive approved for the treatment of heavy menstrual bleeding. Emerging data suggest that $\mathrm{E}_{2} \mathrm{~V} / \mathrm{DNG}$ may be a good alternative to other COCs taken in the conventional $21 / 7$ regimen for women susceptible to hormone-associated withdrawal symptoms, but there is insufficient evidence to conclude whether the effect is due to the components of the formulation or the dosing regimen. Both $\mathrm{E}_{2} \mathrm{~V} / \mathrm{DNG}$ and $\mathrm{E}_{2} / \mathrm{NOMAC}$ generally have minimal influence on hemostatic, lipid, and carbohydrate metabolism parameters, or induce less change in these parameters than EE-based oral contraceptives. Whether these differences can translate into meaningful clinically important outcomes (specifically cardiovascular events) needs to be established in future large-scale prospective studies.

\section{Disclosure}

Jeffrey $\mathrm{T}$ Jensen has received payments for consulting and giving talks for Bayer HealthCare Pharmaceuticals, a company that may have a commercial interest in the results of this research and technology. This potential conflict of interest has been reviewed and managed by Oregon Health and Science University. Jeffrey T Jensen is also a consultant and speaker for Merck Sharp \& Dohme, a consultant for HRA Pharma and Agile Pharmaceuticals, and has received research funding from Abbott Pharmaceuticals, Bayer HealthCare, Warner Chilcott, the Population Council, and the National Institutes of Health. Johannes Bitzer has participated in advisory boards for Bayer HealthCare Pharmaceuticals, Merck Sharp \& Dohme, Lilly, Solvay Pharma, and Boehringer Ingelheim, and has lectured at meetings supported by Bayer HealthCare Pharmaceuticals, Merck Sharp \& Dohme, Lilly, Solvay Pharma, and Boehringer Ingelheim. Marco Serrani is an employee of Bayer HealthCare Pharmaceuticals, the manufacturer of $E_{2} V / D N G$. Richard Glover and Latoya M Mitchell of inScience Communications, Springer Healthcare, provided writing assistance during development of this manuscript. This assistance was funded by Bayer HealthCare Pharmaceuticals.

\section{References}

1. Sitruk-Ware R. New progestagens for contraceptive use. Hum Reprod Update. 2006;12:169-178.

2. Gallo MF, Nanda K, Grimes DA, Lopez LM, Schulz KF. 20 microg versus $>20$ microg estrogen combined oral contraceptives for contraception. Cochrane Database Syst Rev. 2011;1:CD003989.

3. Appel TB, Kambi AA, Birdsall C, et al. A comparison of a new graduated estrogen formulation with three constant-dosed oral contraceptives. Contraception. 1987;35:523-532.

4. Akerlund M, Rode A, Westergaard J. Comparative profiles of reliability, cycle control and side effects of two oral contraceptive formulations containing 150 micrograms desogestrel and either 30 micrograms or 20 micrograms ethinyl oestradiol. Br J Obstet Gynaecol. 1993;100: 832-838.

5. Wyeth-Ayerst Pharmaceutical Inc. Minesse (gestoden $60 \mathrm{ug} / \mathrm{ethinyl}$ estradiol $15 \mathrm{ug}$ ): product monograph; 2001. Available from: http://www. kup.at/kup/monographie/1.pdf. Accessed November 27, 2012.

6. Warner Chilcott. Lo Loestrin Fe: highlights of prescribing information; 2012. Available from: http://www.wcrx.com/pdfs/pi/pi_loloestrinfe.pdf. Accessed January 28, 2013.

7. Gestodene Study Group 322. The safety and contraceptive efficacy of a 24-day low-dose oral contraceptive regimen containing gestodene 60 microg and ethinylestradiol 15 microg. Eur J Contracept Reprod Health Care. 1999;4 Suppl 2:9-15.

8. Gestodene Study Group 324. Cycle control, safety and efficacy of a 24-day regimen of gestodene $60 \mathrm{microg} /$ ethinylestradiol 15 microg and a 21-day regimen of desogestrel $150 \mathrm{microg} /$ ethinylestradiol 20 microg. Eur J Contracept Reprod Health Care. 1999;4 Suppl 2: $17-25$.

9. Reid R; Society of Obstetricians and Gynaecologists of Canada. SOGC clinical practice guideline. No 252, Dec 2010. Oral contraceptives and the risk of venous thromboembolism: an update. J Obstet Gynaecol Can. 2010;32:1192-1204.

10. Kuhl H. Pharmacology of estrogens and progestogens: influence of different routes of administration. Climacteric. 2005;8 Suppl 1:3-63.

11. Jeyakumar M, Carlson KE, Gunther J, Katzenellenbogen JA. Exploration of dimensions of estrogen potency: parsing ligand binding and coactivator binding affinities. J Biol Chem. 2011;286:12971-12982.

12. Kuhnz W, Blode H, Zimmermann H. Pharmacokinetics of exogenous natural and synthetic estrogens and antiestrogens. In: Oettel M, Schillinger E, editors. Handbook of Experimental Pharmacology, Estrogens and Antiestrogens II. Berlin, Germany: Springer-Verlag; 1999.

13. Kuhl H. Pharmacokinetics of oestrogens and progestogens. Maturitas. 1990;12:171-197.

14. Jensen JT, Burke AE, Barnhart KT, et al. Effects of switching from oral to transdermal or transvaginal contraception on markers of thrombosis. Contraception. 2008;78:451-458. 
15. Lindberg UB, Crona N, Stigendal L, Teger-Nilsson AC, Silfverstolpe G. A comparison between effects of estradiol valerate and low dose ethinyl estradiol on haemostasis parameters. Thromb Haemost. 1989;61:65-69.

16. Wiegratz I, Lee JH, Kutschera E, Winkler UH, Kuhl H. Effect of four oral contraceptives on hemostatic parameters. Contraception. 2004;70:97-106

17. Astedt B, Jeppsson S, Liedholm P, Rannevik G, Svanberg L. Clinical trial of a new oral contraceptive pill containing the natural oestrogen 17 beta-oestradiol. Br J Obstet Gynaecol. 1979;86:732-736.

18. Serup J, Bostofte E, Larsen S, Westergaard J. Effectivity and acceptability of oral contraceptives containing natural and artificial estrogens in combination with a gestagen. A controlled double-blind investigation. Acta Obstet Gynecol Scand. 1981;60:203-206.

19. [No authors listed]. A randomized, double-blind study of two combined oral contraceptives containing the same progestogen, but different estrogens. World Health Organization Task Force on Oral Contraception. Contraception. 1980;21:445-459.

20. Schubert W, Cullberg G. Ovulation inhibition with 17 beta-estradiol cyclo-octyl acetate and desogestrel. Acta Obstet Gynecol Scand. 1987;66:543-547.

21. Wenzl R, Bennink HC, van Beek A, Spona J, Huber J. Ovulation inhibition with a combined oral contraceptive containing $1 \mathrm{mg}$ micronized 17 beta-estradiol. Fertil Steril. 1993;60:616-619.

22. Zeun S, Lu M, Uddin A, et al. Pharmacokinetics of an oral contraceptive containing oestradiol valerate and dienogest. Eur J Contracept Reprod Health Care. 2009;14:221-232.

23. Dusterberg B, Nishino Y. Pharmacokinetic and pharmacological features of oestradiol valerate. Maturitas. 1982;4:315-324.

24. Mueck AO, Sitruk-Ware R. Nomegestrol acetate, a novel progestogen for oral contraception. Steroids. 2011;76:531-539.

25. Hoffmann H, Moore C, Zimmermann H, et al. Approaches to the replacement of ethinylestradiol by natural 17 beta-estradiol in combined oral contraceptives. Exp Toxicol Pathol. 1998;50:458-464.

26. Endrikat J, Parke S, Trummer D, et al. Ovulation inhibition with four variations of a four-phasic estradiol valerate/dienogest combined oral contraceptive: results of two prospective, randomized, open-label studies. Contraception. 2008;78:218-225.

27. Ahrendt HJ, Makalova D, Parke S, et al. Bleeding pattern and cycle control with an estradiol-based oral contraceptive: a seven-cycle, randomized comparative trial of estradiol valerate/dienogest and ethinyl estradiol/levonorgestrel. Contraception. 2009;80:436-444.

28. Committee for Medicinal Products for Human use (CHMP). Assessment report: Zoely; 2011. Available from: http://www.ema.europa.eu/ docs/en_GB/document_library/EPAR_-_Public_assessment_report/ human/001213/WC500115833.pdf. Accessed November 28, 2012.

29. Christin-Maitre S, Serfaty D, Chabbert-Buffet N, et al. Comparison of a 24-day and a 21-day pill regimen for the novel combined oral contraceptive, nomegestrol acetate and 17beta-estradiol (NOMAC/ E2): a double-blind, randomized study. Hum Reprod. 2011;26: $1338-1347$.

30. Mansour D, Verhoeven C, Sommer W, et al. Efficacy and tolerability of a monophasic combined oral contraceptive containing nomegestrol acetate and 17 beta-oestradiol in a $24 / 4$ regimen, in comparison to an oral contraceptive containing ethinylestradiol and drospirenone in a 21/7 regimen. Eur J Contracept Reprod Health Care. 2011;16: 430-443.

31. Gerrits MG, Schnabel PG, Post TM, Peeters PA. Pharmacokinetic profile of nomegestrol acetate and 17beta-estradiol after multiple and single dosing in healthy women. Contraception. 2012;87:193-200.

32. Dusterberg B, Schmidt-Gollwitzer M, Humpel M. Pharmacokinetics and biotransformation of estradiol valerate in ovariectomized women. Horm Res. 1985;21:145-154.

33. Timmer CJ, Geurts TB. Bioequivalence assessment of three different estradiol formulations in postmenopausal women in an open, randomized, single-dose, 3-way cross-over study. Eur J Drug Metab Pharmacokinet. 1999;24:47-53.
34. Hirvonen E, Allonen H, Anttila M, et al. Oral contraceptive containing natural estradiol for premenopausal women. Maturitas. 1995;21:27-32.

35. Palacios S, Wildt L, Parke S, et al. Efficacy and safety of a novel oral contraceptive based on oestradiol (oestradiol valerate/dienogest): a Phase III trial. Eur J Obstet Gynecol Reprod Biol. 2010;149: $57-62$.

36. Nelson A, Parke S, Mellinger U, Zampaglione E, Schmidt A. Efficacy and safety of a combined oral contraceptive containing estradiol valerate/dienogest: results from a clinical study conducted in North America. $J$ Womens Health. In press 2013.

37. Fraser IS, Römer T, Parke S, et al. Effective treatment of heavy and/or prolonged menstrual bleeding with an oral contraceptive containing estradiol valerate and dienogest: a randomized, double-blind Phase III trial. Hum Reprod. 2011;26:2698-2708.

38. Jensen JT, Parke S, Mellinger U, Machlitt A, Fraser IS. Effective treatment of heavy menstrual bleeding with estradiol valerate and dienogest: a randomized controlled trial. Obstet Gynecol. 2011;117: 777-787.

39. Westhoff C, Kaunitz AM, Korver T, et al. Efficacy, safety, and tolerability of a monophasic oral contraceptive containing nomegestrol acetate and 17beta-estradiol: a randomized controlled trial. Obstet Gynecol. 2012;119:989-999.

40. Chabbert-Buffet N, Chassard D, Ochsenbein E, et al. Inhibition of ovulation by NOMAC/E2, a novel monophasic oral contraceptive combining nomegestrol acetate and 17beta-oestradiol: a double-blind, randomised, dose-finding pilot study. Eur J Contracept Reprod Health Care. 2011;16:76-84.

41. Hirvonen E, Stenman UH, Malkonen M, et al. New natural oestradiol/ cyproterone acetate oral contraceptive for pre-menopausal women. Maturitas. 1988;10:201-213.

42. Klipping C, Duijkers I, Remmers A, et al. Ovulation-inhibiting effects of dienogest in a randomized, dose-controlled pharmacodynamic trial of healthy women. J Clin Pharmacol. 2012;52: 1704-1713.

43. Spona J, Huber J, Schmidt JB. Inhibition of ovulation with 35 micrograms of ethinyl estradiol and $2 \mathrm{mg}$ cyproterone acetate (Diane 35). Geburtshilfe und Frauenheilkunde. 1986;46:435-438.

44. Hatcher RA, Nelson A. Combined hormonal contraceptive methods. In: Hatcher RA, Trussell J, Stewart F, et al, editors. Contraceptive Technology. 18th ed. New York, NY: Ardent Media Inc; 2004.

45. Bazin B, Thevenot R, Bursaux C, Paris J. Effect of nomegestrol acetate, a new 19-nor-progesterone derivative, on pituitary-ovarian function in women. Br J Obstet Gynaecol. 1987;94:1199-1204.

46. Chretien FC, Dubois R. Effect of nomegestrol acetate on spinability, ferning and mesh dimension of midcycle cervical mucus. Contraception. 1991;43:55-65.

47. Duijkers IJ, Klipping C, Grob P, et al. Effects of a monophasic combined oral contraceptive containing nomegestrol acetate and 17 beta-oestradiol on ovarian function in comparison to a monophasic combined oral contraceptive containing drospirenone and ethinylestradiol. Eur $J$ Contracept Reprod Health Care. 2010;15:314-325.

48. Endrikat J, Parke S, Trummer D, et al. Pituitary, ovarian and additional contraceptive effects of an estradiol-based combined oral contraceptive: results of a randomized, open-label study. Contraception. 2013;87: 227-234.

49. European Medicines Agency. Committee for Medicinal Products for Human use (CHMP). Guideline on clinical investigation of steroid contraceptives in women, 2005. Available from: http://www.ema. europa.eu/docs/en_GB/document_library/Scientific_guideline/2009/09/ WC500003349.pdf. Accessed September 27, 2012.

50. Mansour D, Inki P, Gemzell-Danielsson K. Efficacy of contraceptive methods: a review of the literature. Eur J Contracept Reprod Health Care. 2010;15:4-16.

51. Westhoff CL, Torgal AT, Mayeda ER, et al. Predictors of noncompliance in an oral contraceptive clinical trial. Contraception. 2012;85: 465-469. 
52. Mishell DR Jr, Guillebaud J, Westhoff C, et al. Recommendations for standardization of data collection and analysis of bleeding in combined hormone contraceptive trials. Contraception. 2007;75:11-15.

53. Center for Epidemiology and Health Research, Germany. International Active Surveillance Study - Safety of Contraceptives: Role of Estrogens (INAS-SCORE). Available from: http://clinicaltrials.gov/show/ NCT01009684. NLM identifier: NCT01009684. Accessed September 19, 2013.

54. Center for Epidemiology and Health Research, Germany. Choice of Estrogens and Longterm Investigation of Nomegestrol Acetate - International Active Surveillance Study (INAS-CELINA). Available from: http:// clinicaltrials.gov/show/NCT01650168. NLM identifier: NCT01650168. Accessed on September 19, 2013.

55. Dinger J. Oral contraceptives and venous thromboembolism: old questions revisited. J Fam Plann Reprod Health Care. 2009;35:211-213.

56. Shapiro S, Dinger J. Risk of venous thromboembolism among users of oral contraceptives: a review of two recently published studies. $J$ Fam Plann Reprod Health Care. 2010;36:33-38.

57. Bitzer J, Simon JA. Current issues and available options in combined hormonal contraception. Contraception. 2011;84:342-356.

58. Lidegaard O, Nielsen LH, Skovlund CW, Skjeldestad FE, Lokkegaard E. Risk of venous thromboembolism from use of oral contraceptives containing different progestogens and oestrogen doses: Danish cohort study, 2001-2009. BMJ. 2011;343:d6423.

59. Lidegaard O, Lokkegaard E, Svendsen AL, Agger C. Hormonal contraception and risk of venous thromboembolism: national follow-up study. BMJ. 2009;339:b2890.

60. Dinger JC, Heinemann LA, Kuhl-Habich D. The safety of a drospirenonecontaining oral contraceptive: final results from the European Active Surveillance Study on oral contraceptives based on 142,475 womenyears of observation. Contraception. 2007;75:344-354.

61. Junge W, Mellinger U, Parke S, et al. Metabolic and haemostatic effects of estradiol valerate/dienogest, a novel oral contraceptive: a randomized, open-label, single-centre study. Clin Drug Investig. 2011;31: 573-584.

62. Klipping C, Duijkers I, Parke S, et al. Hemostatic effects of a novel estradiol-based oral contraceptive: an open-label, randomized, crossover study of estradiol valerate/dienogest versus ethinylestradiol/ levonorgestrel. Drugs R D. 2011;11:159-170.

63. Agren UM, Anttila M, Maenpaa-Liukko K, et al. Effects of a monophasic combined oral contraceptive containing nomegestrol acetate and 17beta-oestradiol compared with one containing levonorgestrel and ethinylestradiol on haemostasis, lipids and carbohydrate metabolism. Eur J Contracept Reprod Health Care. 2011;16:444-457.

64. Gaussem P, Alhenc-Gelas M, Thomas JL, et al. Haemostatic effects of a new combined oral contraceptive, nomegestrol acetate/17beta-estradiol, compared with those of levonorgestrel/ethinyl estradiol. A double-blind, randomised study. Thromb Haemost. 2011;105:560-567.
65. Grimes DA, Schulz KF, Raymond EG. Surrogate end points in women's health research: science, protoscience, and pseudoscience. Fertil Steril. 2010;93:1731-1734.

66. Schindler AE, Campagnoli C, Druckmann R, et al. Classification and pharmacology of progestins. Maturitas. 2003;46 Suppl 1: S7-S16.

67. Grimes DA, Schulz KF. Nonspecific side effects of oral contraceptives: nocebo or noise? Contraception. 2011;83:5-9.

68. Sordal T, Grob P, Verhoeven C. Effects on bone mineral density of a monophasic combined oral contraceptive containing nomegestrol acetate/17beta-estradiol in comparison to levonorgestrel/ethinylestradiol. Acta Obstet Gynecol Scand. 2012;91:1279-1285.

69. Fraser IS, Parke S, Mellinger U, et al. Effective treatment of heavy and/or prolonged menstrual bleeding without organic cause: pooled analysis of two multinational, randomised, double-blind, placebo-controlled trials of oestradiol valerate and dienogest. Eur J Contracept Reprod Health Care. 2011;16:258-269.

70. Fraser IS, Jensen J, Schaefers M, et al. Normalization of blood loss in women with heavy menstrual bleeding treated with an oral contraceptive containing estradiol valerate/dienogest. Contraception. 2012;86: 96-101.

71. Wasiak R, Filonenko A, Vanness DJ, et al. Impact of estradiol-valerate/ dienogest on work productivity and activities of daily living in European and Australian women with heavy menstrual bleeding. Int $J$ Womens Health. 2012;4:271-278.

72. Wasiak R, Filonenko A, Vanness DJ, et al. Impact of estradiol valerate/ dienogest on work productivity and activities of daily living in women with heavy menstrual bleeding. Int J Womens Health. 2013;22: 378-384.

73. Jensen JT, Parke S, Mellinger U, Serrani M, Mabey R Jr. Hormone withdrawal-associated symptoms: comparison of oestradiol valerate/ dienogest versus ethinylestradiol/norgestimate. Eur J Contracept Reprod Health Care. 2013;18:274-283.

74. Macìas G, Merki-Feld GS, Parke S, Mellinger U, Serrani S. Effects of a combined oral contraceptive containing estradiol valerate/dienogest on hormone withdrawal-associated symptoms: results from the multicentre, randomised, double-blind, active-controlled, HARMONY II study. J Obstet Gynecol. 2013;33:591-596.

75. Nappi RE, Davis SR, Bitzer J, et al. Effects on libido of estradiol valerate/ dienogest compared to ethinyl estradiol/levonorgestrel. Endocr Rev. 2011;32:P1-P315.

76. Caruso S, Agnello C, Romano M, et al. Preliminary study on the effect of four-phasic estradiol valerate and dienogest (E2V/DNG) oral contraceptive on the quality of sexual life. J Sex Med. 2011;8: 2841-2850.
Open Access Journal of Contraception

\section{Publish your work in this journal}

Open Access Journal of Contraception is an international, peerreviewed, open access, online journal, publishing original research, reports, reviews and commentaries on all areas of contraception. In addition to clinical research, demographics and health-related aspects, the journal welcomes new findings in animal and preclinical studies
Dovepress

relating to understanding the biological mechanisms and practical development of new contraceptive agents. The manuscript management system is completely online and includes a very quick and fair peer-review system. Visit http://www.dovepress.com/testimonials.php to read real quotes from published authors. 